\title{
Comentários sobre política internacional ${ }^{*}$
}

\author{
OTTO MARIA CARPEAUX
}

\section{Um profeta \\ C(T E MONDE", o grande jornal parisiense, não precisa ser elogiado. É órgão do mais alto nível intelectual. Não tem compromissos com nenhum partido, nem de governo nem de oposição, e com nenhuma} ideologia. Jornal pobre de recursos materiais, é de altiva independência.

Os artigos e reportagens publicados durante a semana saem depois numa edição hebdomadária que é lida no mundo inteiro. Transportada por avião para Istambul e para Nova York, para Delhi e para o Rio de Janeiro, para a Cidade do Cabo e para Estocolmo, costuma, no entanto, chegar com algum atraso, devido à insuficiência dos serviços postais. Desse modo, só ontem, dia 4 de abril, nos chegou às mãos o número de 25 de março, do qual consta uma reportagem de Washington, intitulada: "Depois da mensagem presidencial ao Congresso Nova diminuição da ajuda americana ao estrangeiro".

Diz o correspondente de "Le Monde" que a ajuda ao estrangeiro proposta pelo presidente Lyndon Johnson é sensivelmente inferior à do ano passado. A prioridade caberá à Ásia: quase totalmente, ajuda militar. A América Latina deverá receber 570 milhões, sendo que nem todos os governos latino-americanos são considerados dignos de ajuda. Pretenderia o governo norte-americano abandonar a tese do presidente Kennedy de que "a presença dos Estados Unidos não deverá ficar totalmente ligada aos interesses da indústria americana”. O novo subsecretário de Estado, Sr. Thomas C. Mann, insistiria no respeito integral aos investimentos norte-americanos particulares na América Latina, sob pena de supressão da ajuda. E dessa nova doutrina “dura” já se começaria a tirar consequências na prática.

Essas hipóteses, baseadas num discurso do Sr. Mann perante os embaixadores dos Estados Unidos na América Latina, pareciam tornar necessário um desmentido oficial. Um porta-voz do Departamento de Estado afirmou que “a política americana com respeito aos governos inconstitucionais continuará determinada, como no passado, pelo interesse nacional e pelas circunstâncias, próprias de cada uma das situações”. Com essa declaração pretendeu-se desmentir as afirmações sobre o discurso do Sr. Thomas C. Mann na conferência dos embaixadores dos Estados Unidos na América Latina. Mas logo se verá que não é desmentido, e, sim, confirmação.

Pois o Sr. Thomas C. Mann teria declarado, naquela conferência, que “o 
Governo de Washington desiste da sua política de oposição sistemática aos golpes militares". Como se vê, aquele porta-voz do Departamento de Estado quis desmentir, mas não conseguiu: confirmou inabilmente as declarações atribuídas ao Sr. Thomas C. Mann.

E agora essa reportagem de 25 de março chegou ao Rio de Janeiro no dia 4 de abril, três dias depois de grandes acontecimentos. O Sr. Thomas C. Mann não é, como se sabe, idêntico com o grande escritor Thomas Mann. Não é um intelectual. Mas é um profeta.

$(5 / 4 / 1964)$

\section{Diferença}

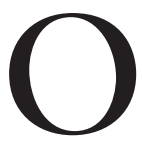

DOCUMENTo básico para as discussões na Conferência Internacional de Comércio e Desenvolvimento, em Genebra, foi o relatório Raul Prebisch: observando a permanente queda dos preços das matérias-primas exportadas pelos países subdesenvolvidos, explica, assim, os déficits de pagamento desses países que já não estão em condições de financiar suas importações. Essa dificuldade atinge os países industrializados, exportadores de produtos manufaturados. Remédio radical seria a industrialização dos países subdesenvolvidos. Já começou esse processo. Mas este, por sua vez, está perturbando o desenvolvimento agrícola, que é muito mais lento; desequilíbrio que é a fonte principal da inflação. Tampouco seria desejável a industrialização total do mundo inteiro, por que acabaria com o comércio internacional e levaria, provavelmente, a guerras para fins de conquista de mercados. Raul Prebisch exige, portanto, duas séries de medidas: 1) da parte dos países desenvolvidos, a estabilização dos preços das matérias-primas, em níveis mais altos que os atuais, ou então, o financiamento compensatório de quedas dos preços; 2) da parte dos países subdesenvolvidos, reforma agrária, reforma tributária e planejamento econômico.

Os representantes dos países desenvolvidos concordaram em participar da Conferência, porque a falência dos subdesenvolvidos os privaria de grandes mercados. Mas levantam certo número de objeções. No fundo, opõem-se à proposta de estabilizar os preços das matérias-primas, porque na economia de mercado livre não pode haver estabilização alguma sem abolir a liberdade econômica. Quando muito, estão dispostos a permitir a fixação de preços máximos e preços mínimos para evitar oscilações excessivas. Mas mesmo assim levantam outra objeção, muito mais importante: é o receio de que preços melhores e estáveis possam incentivar o aumento da produção e causar a superprodução que em certos artigos (café etc.) já existe.

O Sr. Raul Prebisch não desconhece esse perigo. Justamente para evitá-lo propõe a reforma agrária nos países latino-americanos, para obrigar a agricultura a diversificar a produção e abandonar a monocultura exportadora. 
Essa argumentação encontra muita compreensão na Europa. Temos em mãos o número especial, em espanhol, de 19 de dezembro de 1963, da revista Das Parlament, editada oficialmente pelo Parlamento da República Federal da Alemanha, em Bonn. Nesse número lemos: "Un grave problema estructural representa la monocultura de algunos productos agricolas... Solamente el café supone un $60 \%$ de las exportaciones brasileñas y un 77\% de las colombianas". A revista afirma que "la monocultura frena el mejoramiento de la productividad". Mas em que se baseia essa monocultura. Na concentração da produção agrícola em número reduzido de propriedades rurais, comercialmente administradas. Continua a revista:

La necesidad de reformar la constitución agraria demuestran algunas cifras sobre el actual repartimiento de propiedades. En 19 paises latino-americanos se encuentran más o menos dos terceras partes (65\%) de la tierra labrada en manos de solo e 1,47\% de propietarios de grandes haciendas... Se debe apoyar el programa de las reformas agradas que conduzcan bacia un cambio efectivo de la estructuración y de la injusta repartición de la propiedad de la tierra.

Esse programa não tem, porém, expectativas de ser realizado. Pois na Alemanha pode ser preconizado por uma revista oficial, editada por um Parlamento com maioria católico-conservadora, num país governado pelos conservadores e no qual o partido comunista é ilegal. Mas na maior parte dos países latino-americanos passa por subversivo aquele programa. É a diferença.

\section{Revolução e legitimidade}

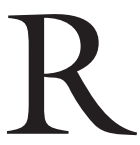
EFERINDO-SE às guerrilhas de oposicionistas na Kabylia, o presidente Ben Bella, da Argélia, acaba de declarar (e citamos literalmente): "Esmagaremos todos os que tentarem opor-se à legitimidade revolucionária".

Ouvimos com a maior surpresa a expressão citada. Legitimidade revolucionária? Que vem a ser isso? Legitimidade e Revolução não seriam conceitos contrários, antagônicos, incompatíveis? Pelo menos depois de 1815, na época da Restauração, todo o mundo conservador pensava assim e o papa Gregório XVI, na Encíclica "Mirari vos", de 1832, confirmou a tese, condenando toda e qualquer revolução como atentado ímpio ao poder legítimo.

Mas acontece que hoje em dia todos os governos parecem "ímpios". Da França, com sua série ininterrupta de revoluções, de 1789 a 1958, nem se fala. Nem da Itália, cujo próprio ato de formação, a unificação de 1860, foi declarado ilegítimo, falando os papas até 1929 só em "governo subalpino". Ímpia é a origem do governo de Portugal, não somente a partir do golpe de Estado salazarista de 1926, mas já desde 1910 quando foi deposto o último rei. Até o poder da rainha da Inglaterra baseia-se, em última linha, na "Glorious Revolution" de 1688, que expulsou a dinastia escocesa dos Stuart; por isso alguns clubes de aristocratas escoceses ultraconservadores não reconhecem até hoje a legitimidade da rainha Elisabeth II, chamando-a, pitorescamente, "Mrs. Mountbatten". 
Acrescentamos que o poder do governo soviético, baseado na revolução de 1917, é tão "ilegítimo" como o poder do governo dos Estados Unidos, baseado na revolução de 1776. Estão no mesmo caso todos os governos, passados, presentes e futuros, de todos os países latino-americanos, sem exceção alguma.

Sendo tão generalizada a "ilegitimidade", é estranhável que todos os governos "revolucionários", e, portanto, "ilegítimos", procurem tenazmente serem reconhecidos como legítimos. Não satisfeitos com o poder, também o querem juridicamente justificado. Comportam-se como arrombador de cofre que, depois de ter roubado o dinheiro e as joias, pede ao ex-proprietário e à polícia que assinem documentos com firma reconhecida, atestando a legitimidade da transação. Por que será isso?

Não há dúvida: sempre é possível arranjar atestados daqueles. A jurisprudência não é uma ciência, mas uma técnica. Não procura verdades, mas interpreta fatos. Serve. Donoso Cortès, o célebre ideólogo espanhol da reação conservadora e absolutista, disse sobre os juristas franceses da Revolução que forneceram argumentos aos regicidas, condenando à morte o rei Louis XVI: "Depois dos sofistas, chegam os carrascos". Hoje se observa a ordem contrária: depois dos carrascos, chegam os sofistas.

Mas por que todos os revolucionários modernos insistem tanto em legitimar a revolução, embora esta por definição não possa ser legítima? Porque esperam com isso estigmatizar e anatematizar de antemão todas as futuras revoluções que poderiam chegar a arrancar-lhes o poder. Só essas futuras revoluções seriam, sim, ilegítimas porque dirigidas contra a revolução legitimada. É, evidentemente, uma conclusão errada. Pois os mesmos argumentos que justificam e legitimam esta ou aquela revolução justificam e legitimam todas as revoluções futuras.

$(7 / 5 / 1964)$

\section{A descida da latitude}

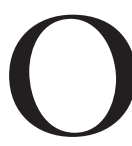

S ADVERSÁRIOS do movimento militar de abril de 1964 costumam reprochar aos movedores que estes não sabem definir exatamente a natureza e os rumos da marcha iniciada. Mas esses próprios adversários tampouco chegam a dar um nome incontrovertido às coisas.

Às vezes falam em retrocesso, como se o movimento de abril tivesse ressuscitado ou revivificado uma fase já superada do passado histórico; mas logo depois afirmam que "o Brasil nunca experimentou nada de parecido". Como, então, pode-se falar em retrocesso? Seria mais exato dizer novidade.

Mas negam isso. Novidade, dizem, talvez no Brasil, mas não na América Latina; querem dizer, na América Espanhola. Afirmam que acontecimentos parecidos com o de abril de 1964 seriam frequentes e rotineiros na maior parte das Repúblicas hispano-americanas. E falam em hispano-americanização do Brasil. 
É outra expressão inexata, ou antes: mal definida. Supõe a homogeneidade do bloco de países hispano-americanos, ao passo que conhecemos bem as imensas diferenças entre eles. Também supõe a semelhança rotineira dos acontecimentos políticos nesses países - generais politiqueiros, conspirações, golpes de Estado e pseudorrevoluções, isto é, revoltas que não mudam a estrutura do país -, assim como a América Espanhola se afigura aos europeus e norte-americanos menos informados que falam em là-bas ou South of the Rio Grande. Mas assim não temos o direito de pensar, sendo muito melhor, mais volumosa e mais exata nossa informação sobre o continente. Apenas essa informação costuma ser caótica. Não se dispõe de critérios seguros para pôr em ordem compreensível as coisas.

Um critério assim pretende-se propor no presente comentário. É o seguinte: as diferenças enormes entre os países hispano-americanos causam iguais diferenças entre caudilhos e caudilhos, generais e generais, golpes e golpes, ditaduras e ditaduras; e o exame atento dessas diferenças permite distinguir dois tipos de ditaduras. hispano-americanas: as do norte do continente e as do sul do continente (denominadas, a partir de agora, ditadura nortista e ditadura sulista). Não são parecidas. São antagônicas.

Um precursor rude, por assim dizer informe, do tipo sulista foi o argentino Rosas, que hostilizou o comércio dos estrangeiros, governando com os aplausos da população de Buenos Aires. Precursor de outro quilate foi Balmace$\mathrm{da}$, que pretendia libertar o Chile do abraço sufocador das grandes companhias estrangeiras e que se voltou contra o Congresso porque este estava dominado pelos latifundiários e pelos advogados daquelas companhias; por isso os liberais denunciaram-lhe o cesarismo demagógico. Mas o protótipo da ditadura sulista é Peron: antiparlamentarismo, demagogia antidemocrática, legislação social baseada em vagas ideias pseudossocialistas, nacionalismo econômico, hostilizando os grupos estrangeiros. Esse tipo está bem definido.

E no Brasil? Com alguma razão ou com muita razão atribuem-se traços do tipo sulista à ditadura do Estado Novo getulista. Observadores hispano-americanos atribuíram-lhe também o cesarismo democrático. Mas é, na história brasileira, um caso isolado. Por isso mesmo muitos historiadores e comentaristas brasileiros ficavam perplexos em face do fenômeno. Também já estavam perplexos os adversários do marechal Floriano Peixoto. A este também atribuíram a vontade de hispano-americanizar o país; mas o marechal desmentiu-os, não ambicionando a prorrogação do seu mandato. No entanto, há em Floriano certos traços do tipo sulista: foi, até certo ponto, nacionalista econômico; não quis vender a financistas estrangeiros a Estrada de Ferro Central do Brasil, ao passo que um ditador de tipo nortista teria sido "eleito" e empossado justamente para efetivar essa transação.

Pois a ditadura hispano-americana de tipo nortista é justamente o contrário do tipo sulista. 
Pode ser chamado nortista porque é fenômeno próprio do Norte da América Latina: domina há século e meio as Repúblicas da América Central, ilhas do Caribe e, principalmente, a Venezuela (com incursões casuais na Colômbia e no Peru). O representante mais conhecido desse tipo foi Juan Vicente Gómez, que durante 27 anos dominou com mão de ferro a Venezuela, "reelegendo-se" sempre e enchendo as prisões com adversários torturados; ditador, beneficiando as companhias de petróleo e sendo beneficiado por elas; teve, mais tarde, sucessor digno na pessoa do coronel Pérez Jiménez, que "aperfeiçoou" o sistema penitenciário e acrescentou aos recursos para manter-se no poder o pagamento de vencimentos totalmente exagerados aos militares. Todos os ditadores de tipo nortista fazem questão de dissimular a natureza do poder que exercem: mantêm em pé a fachada de instituições representativas e às vezes até permitem a realização de eleições mais ou menos livres; mas se, porventura, uma eleição dessas lhes for desfavorável, anulam o resultado (como fez Pérez Jiménez em 1952).

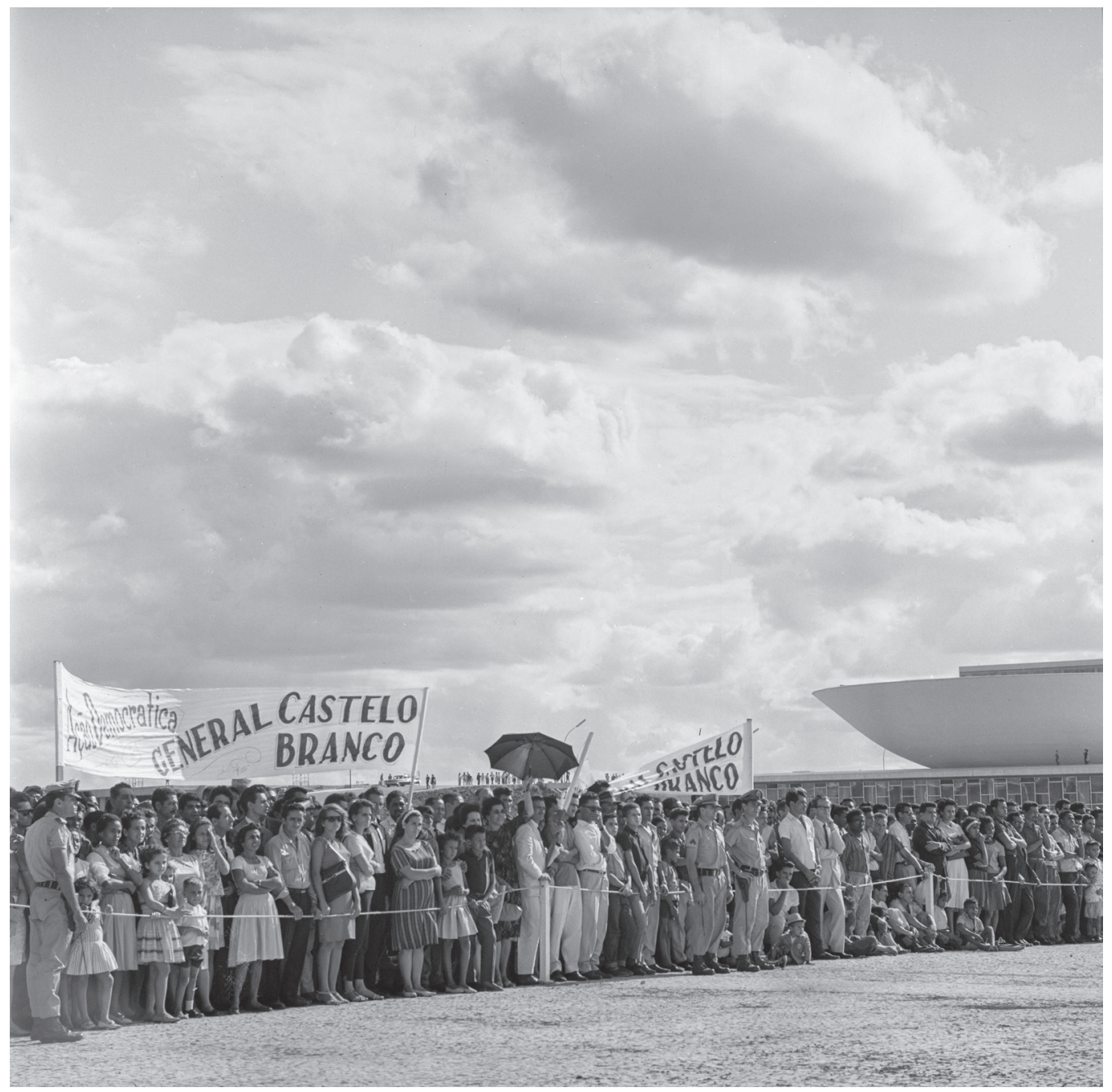

Homens, mulheres e crianças saúdam com faixas o presidente Castelo Branco em Brasilia. 


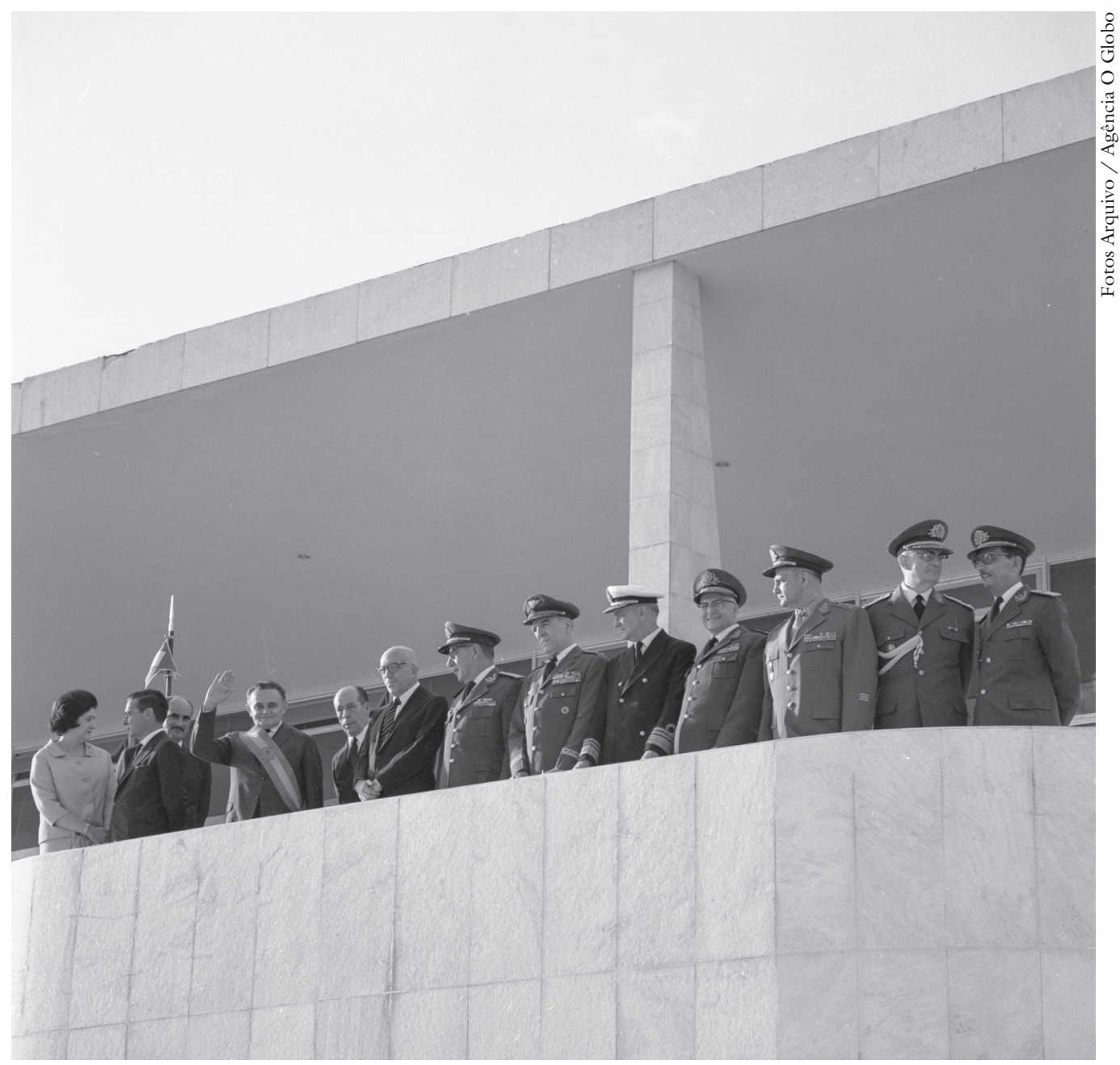

O presidente Castelo Branco acena para a população durante a sua posse em 15 de abril de 1964.

São, todos eles, generais instalados com o beneplácito de empresas estrangeiras e exercem a ditadura até o momento em que essas empresas chegam a preferir outro general; é o momento do golpe. Na Venezuela, o interesse que vinculou o ditador aos seus financiadores foi o petróleo; na Guatemala, são as bananas da United Fruit Co.; na Nicarágua e República Dominicana (e, antigamente, em Cuba), o açúcar, e no Panamá, o canal. Além dessas diferenças econômicas existe a dos temperamentos: o ditador guatemalteco general Jorge Ubico que tiraniza seus súditos conforme as denúncias fornecidas pelo seu serviço de informações, instalado em restaurantes e bordéis; o hondurenho Marco Aurelio Soto que se julgava intelectual e poeta e ao qual a maledicência dos seus adversários atribuiu o hábito de pronunciar conferências literárias, colocando em cima da mesa duas metralhadoras para impressionar favoravelmente a crítica; e o venezuelano general Cipriano Castro pela resposta que deu no leito de morte à pergunta do padre que veio confessá-lo: “O general perdoa aos seus inimigos?”, e o agonizante respondeu: "Não tenho inimigos, mandei fuzilá-los todos”. Há, também, tem- 
peramentos mais paternalistas, homens ponderados como o hondurenho Tiburcio Carías que, não fazendo mal, pessoalmente, a ninguém, mal suportou - mas suportou - os desmandos dos seus subordinados. Acima dessas diferenças todas verificam-se os traços e característicos das ditaduras de tipo nortista: a aversão contra o populismo dos sulistas e a rejeição de todo e qualquer socialismo ou medidas socializantes; o repúdio ao nacionalismo econômico; o respeito formal à fachada das instituições representativas; o apelo ao apoio das chamadas elites que acrescentam à base militar do poder os argumentos jurídicos, justificando as inevitáveis medidas de exceção, isto é, de violência.

A bibliografia sobre história política latino-americana é enorme. Ninguém seria capaz de dominá-la inteira. É possível que a distinção aqui proposta entre o cesarismo democrático dos ditadores sulistas e o gendarme necessário (Vallenilla Lanz) da ditadura nortista já teria ocorrido a outros observadores. Nesse caso, seria nova apenas a verificação de que essa distinção geográfica entre Norte e Sul admite exceções. Então, essa relativa originalidade da tese permitirá enquadrar no esquema o caso brasileiro. Conforme a posição geográfica, só poderia surgir, no Brasil, o tipo sulista; e já surgiu, efemeramente, em Getulio. Se o regime atual do Brasil apresentar, porventura, traços nortistas, resta procurar para esse fenômeno inesperado uma terminologia tirada da história nacional. Procuraremos criar o termo. Em passado remoto, o Brasil já foi modificado pelo Recuo do Meridiano. O fato atual seria, via de analogia, a Descida da Latitude.

O Recuo do Meridiano ampliou as dimensões do Brasil, engrandecendo-o. Esperamos as consequências geométrico-espirituais da Descida da Latitude.

Otto Maria Carpeaux (9 de março de 1900 - Áustria - 3 de fevereiro de 1978). Cidadão austríaco e brasileiro, estudou matemática, física e química na Universidade de Viena, onde se doutorou em Letras e Filosofia. Paralelamente, dedicou-se à musica e às ciências humanas, orientando-se na linha de pensamento que vai do historicismo alemão à dialética da História. Patriota, combateu o nazismo e a anexação da Áustria pela Alemanha, tendo sido obrigado (1938) a refugiar-se na Bélgica. Em 1939 emigrou para o Brasil, onde escreveu a maior parte de sua obra (já publicara cinco livros na Europa): A cinza do purgatório, ensaios (1942); Origens e fins (1943); Pequena bibliografia critica da literatura brasileira (1949-1963); Respostas e perguntas, ensaios (1953); Retratos e leituras (1953); Presenças (1958); História da literatura Ocidental, 8v. (1958-1966); Uma nova história da música (1958); Livros na mesa, ensaios (1960); A literatura alemã (1964); O Brasil no espelho do mundo, artigos políticos (1965); A batalha da América Latina (1966); 25 anos de literatura (1968); além de outros livros e numerosos prefácios, introduções, verbetes de enciclopédia.

* Reproduzidas de: CARPEAUX, O. M. O Brasil no espelho do mundo. Rio de Janeiro: Civilização Brasileira, 1965. p.7-8, p.13-4 e p.21-2, respectivamente. E CARPEAUX, O. M.. A descida da Latitude. In: A batalha da América Latina. Rio de Janeiro:

Civilização Brasileira, 1965. p.24-7. 